
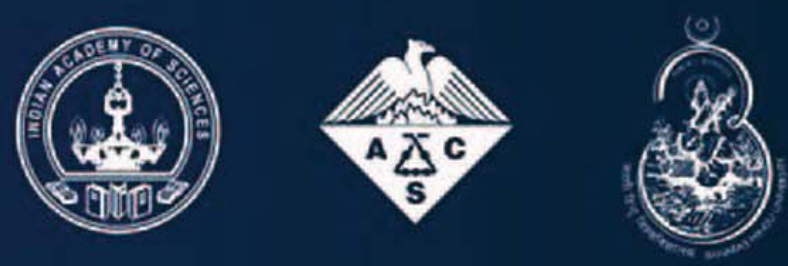

Indian Academy of Sciences - ACS Publications Forum

\title{
EXPANDING FRONTIERS IN CHEMICAL SCIENCES
}

organised on the sidelines of the 84th Annual Meeting of Indian Academy of Sciences

DATE: 1 November 2018

\section{FEATURING}

\section{SPECIAL SPEAKER}

\section{Professor C.N.R. Rao}

Editorial Advisory Board, ACS Nano

Linus Pauling Research Professor \& Honorary

President, Jawaharlal Nehru Centre for

Advanced Scientific Research, Bengaluru

\section{PLENARY SPEAKERS}

Professor Anne Milasincic Andrews

Associate Editor, ACS Chemical Neuroscience

Editorial Advisory Board, ACS Sensors

Brain Research Institute, University of Cali.

fornia, Los Angeles

Professor Swagata Dasgupta

Dept. of Chemistry, Indian Institute of Tech-

nology, Kharagpur

Professor Sandeep Verma

Head, Dept. of Chemistry, Indian Institute of

Technology, Kanpur

Professor Paul Weiss

Editor-in-Chief, ACS Nano

Distinguished Professor, Dept. of Chemistry

$\&$ Biochemistry and the Dept. of Materials

Science \& Engineering, University of Califor-

nia, Los Angeles
VENUE: Banaras Hindu University, Varanasi

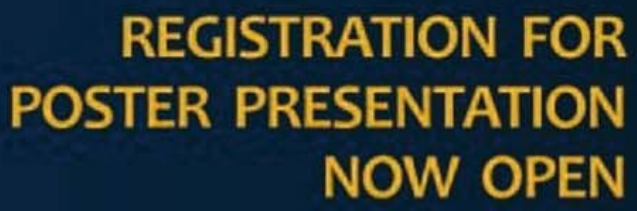

ABSTRACT SUBMISSION DEADLINE

5 October 2018

PROGRAMME INCLUDES

Plenary talks

Short Lectures

Poster Presentations Networking Opportunities

For further information and registration, visit bit.ly/iasforum

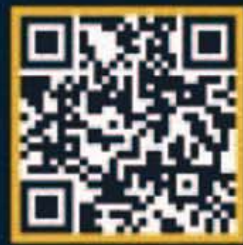

